\title{
Refractory Monomorphic Post-Transplant Lymphoproliferative Disorder
}

National Cancer Institute

\section{Source}

National Cancer Institute. Refractory Monomorphic Post-Transplant Lymphoproliferative Disorder. NCl Thesaurus. Code C157475.

A monomorphic post-transplant lymphoproliferative disorder that does not respond to treatment. 